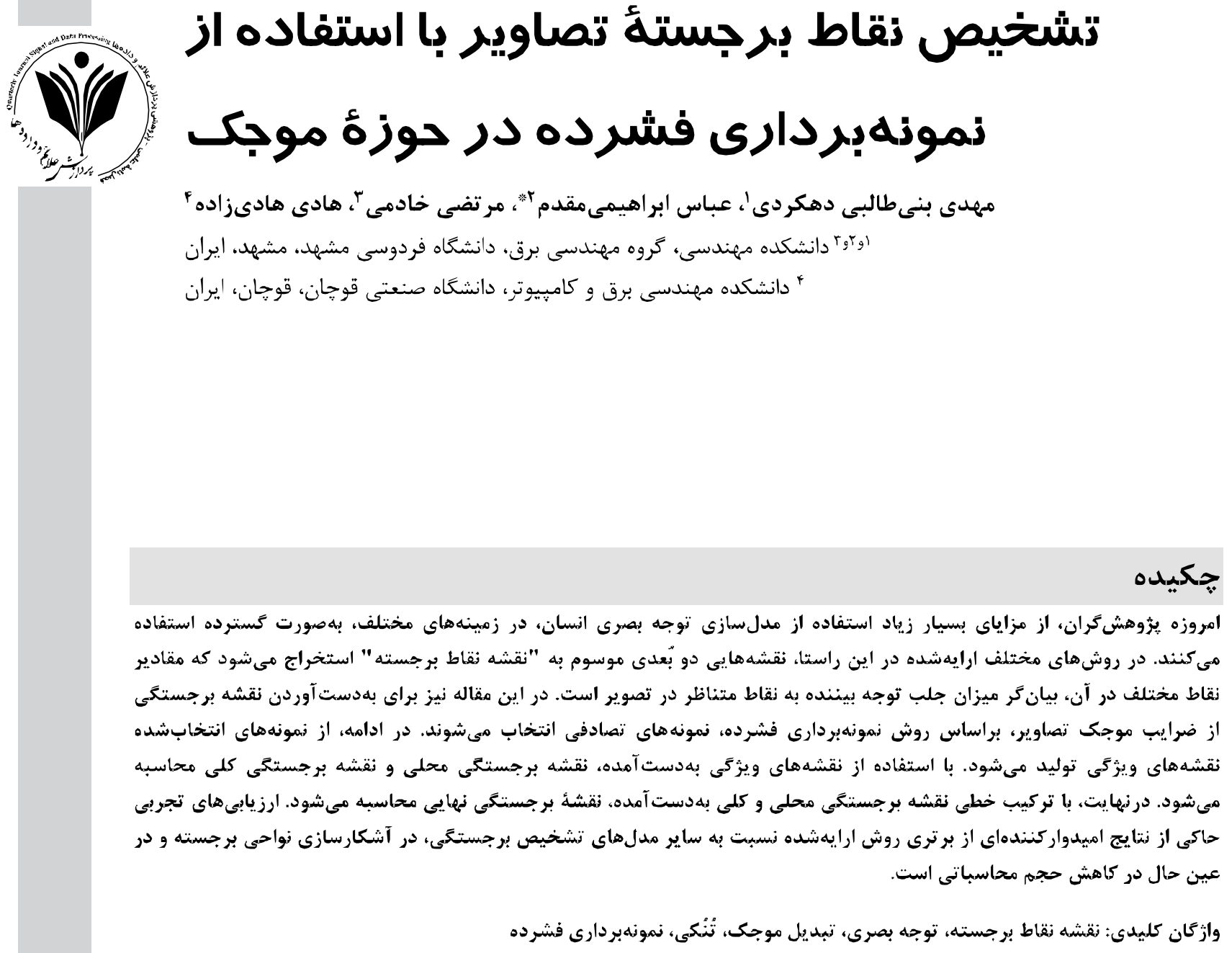

\title{
Compressed-Sampling-Based Image Saliency Detection in the Wavelet Domain
}

\author{
Mehdi Banitalebi-Dehkordi ${ }^{1}$, Abbas Ebrahimi-Moghadam ${ }^{2 *}$, Morteza Khademi ${ }^{3}$, \\ Hadi Hadizadeh ${ }^{4}$ \\ ${ }^{1,2,3}$ Faculty of Engineering, Department of Electrical Engineering, University of Mashhad, \\ Mashhad, Iran \\ ${ }^{4}$ Faculty of Electrical and Computer Engineering, Quchan University of Technology, \\ Quchan, Iran
}

\section{Abstract}

When watching natural scenes, an overwhelming amount of information is delivered to the Human Visual System (HVS). The optic nerve is estimated to receive around $10^{8}$ bits of information a second. This large amount of information can't be processed right away through our neural system. Visual attention mechanism enables HVS to spend neural resources efficiently, only on the selected parts of the scene at order. This results in a better and faster perception of events.

In order to perform saliency measurement on visual data, subjective eye-tracking experiments may be carried out. These experiments involve using devices to track eye movements of a number of subjects while they watch images or videos on a screen.

That being said, such devices are not very suitable in practice due to hardship involved with carrying out experiments, such as need to have restricted test environment, being time consuming as well as expensive. 
Instead, researchers developed Computational Visual Attention Models (VAMs) in attempts to mimic the HVS saliency prediction process.

Visual Attention Modelling has widely been used in various areas of image processing and understanding. Computational models of visual attention aim to predict the most interesting areas of an image to the observers. To this end, these models produce saliency maps, in which each pixel is assigned a likelihood value of being looked at. In other words, saliency maps highlight where the most likely for viewers to look at in an image is. Knowing the Regions of Interests (ROIs) can be helpful in applications such as image and video compression, object recognition and detection, visual search, retargeting, retrieval, image matching, and segmentation.

Saliency prediction is generally done in a bottom-up, top-down, or hybrid fashion. Bottom-up approaches exploit low-level attributes such as brightness, color, edges, texture, etc. Top-down approaches focus on context-dependent information from the scene such as appearance of humans, animals, text, etc. Hybrid methods combine the two streams.

This paper proposes a new method of saliency prediction using sparse wavelet coefficients selected from low-level bottom-up saliency features. Wavelet based image methods are used widely in image processing algorithms as they are especially powerful in decomposing images into several scales of resolutions. In our method, first random compressive sampling is performed on wavelet coefficients in the Lab color space. Random sampling enables a reduction in computational complexity and provides a sparse representation of the coefficients. The number of decomposition levels is chosen based on the information diffusion property of the signal. In the proposed method, the sampling can be done at a rate different than the Nyquist rate, and based on the sparsity degree of the signal. It is shown that having the basis vectors of a sparse representation of the signal, can result in an accurate signal reconstruction. In this work, the sparsity degree and thus the sampling rate is computed empirically. Next, local and global saliency maps are generated from these random samples to account for small-scale and large-scale (scene-wide) saliency attributes. These maps are then combined to form an overall saliency map. The overall saliency map therefore includes both local, and global saliency attributes. The main contribution of this paper is the use of compressive sampling in creating a novel wavelet domain representation for image saliency prediction.

Extensive performance evaluations show that the proposed method provides a promising saliency prediction performance while the computation complexity remains reasonable, thanks to the dimensionality reduction of compressive sampling. In particular, the proposed method demonstrated favorable precision, recall, and F-measure, when compared to state-of-the-art saliency detection methods, over large-scale datasets. We hope the proposed approach brings ideas to the saliency analysis research community.

Keywords: Saliency map, visual attention, wavelet transform, sparsity, compressive sampling

$$
\begin{aligned}
& \text { يثوهثهاى فراوانى جهت مطالعه و درك اين سازوكار } \\
& \text { صورت گرفته است و مدله هاى هحاسباتى هختلفى براى } \\
& \text { يِشبينى نقاط برجسته در تصاوير ديجيتال طراحى و توسعه } \\
& \text { يافته|زد [5-8]. } \\
& \text { در حالت كلى مىتوان روشهاى موجود براى زهاى } \\
& \text { ييشبينى نقاط برجسته در يكى تصوير را به دو دسته }
\end{aligned}
$$

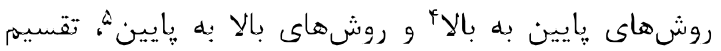

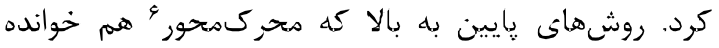

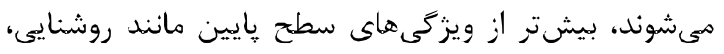

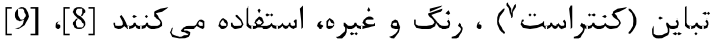

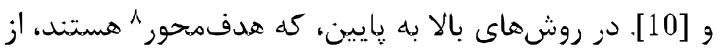

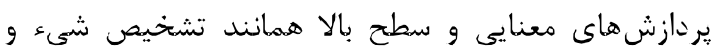

$$
\begin{aligned}
& \text { متن براى بيشبينى زقاط برجسته استفاده مىكنيند [11]، }
\end{aligned}
$$

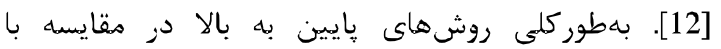

\footnotetext{
${ }^{4}$ Bottom-Up

${ }^{5}$ Top-Down

${ }^{6}$ Stimulus- Driven

${ }^{7}$ Contrast

${ }^{8}$ Goal-Driven
}

$$
\begin{aligned}
& \text { dodقo - } 1 \\
& \text { در هر ثانيه در حدود ^^• ا بيت اطلاعات از جشهمها به مغز }
\end{aligned}
$$

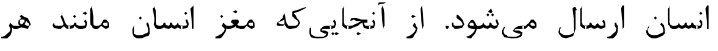

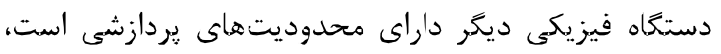

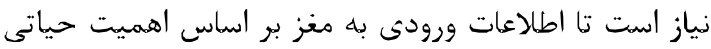

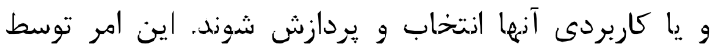

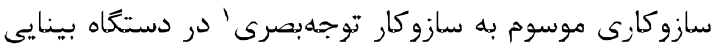

$$
\begin{aligned}
& \text { انسان (HVS } \\
& \text { سازوكار، هكان جلب توجه انسان در هنكام مشاهده يك رئ } \\
& \text { تصوير يا يك صحنه تصويرى مشخص مىشود. درك سازوكار }
\end{aligned}
$$

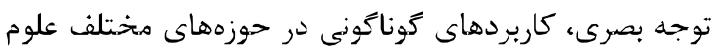

$$
\begin{aligned}
& \text { كاربردى و و مهندسى دارد. درحقيقت، يِيشبينى زنقاط }
\end{aligned}
$$

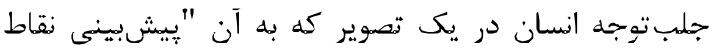

$$
\begin{aligned}
& \text { برجسته r" تفته مى شود، كابردهاى زيادى در بينايى رايانه، }
\end{aligned}
$$

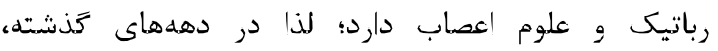


در روش بيشننهادى Achenta و همكاران [17]، براى

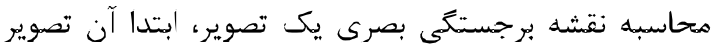

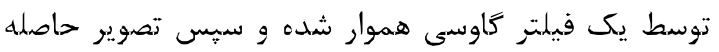
به فضاى رنكى CIE-LAB

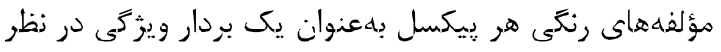

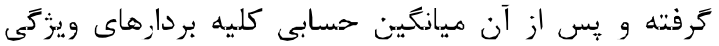

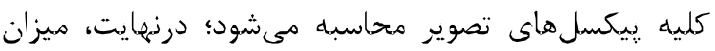

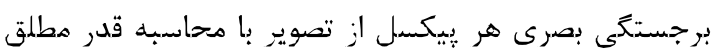

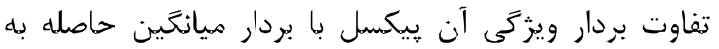

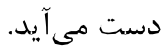
بلهور كلى، مدل هايى همانند مدل Itti و GBVS از

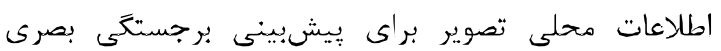
استفاده مى كنند، درحالى كه مدلهايى نظير مدل ارلى ارايهشده توسط Hou و همكاران و همجنجين مدل ارايهشده توسط Achenta

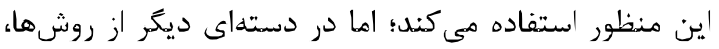

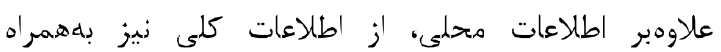
اطلاعات هحلى استفاده شده است. از جملهُ اين روشهات إنهات

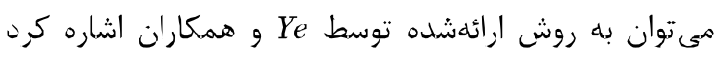

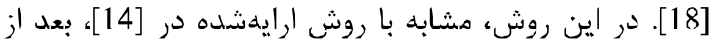

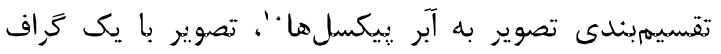

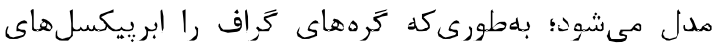

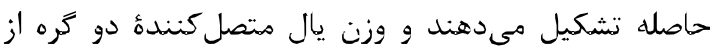

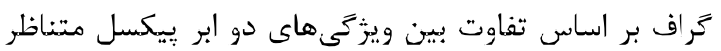

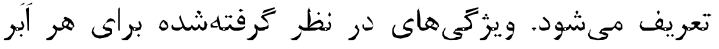

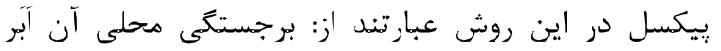

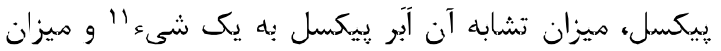

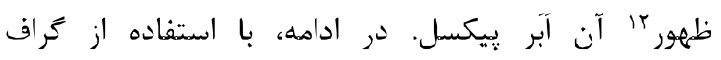

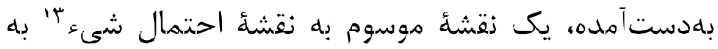

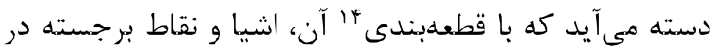
تصوير از زمينه تفكيك و شناساييى مي شئدوند.

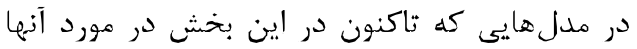

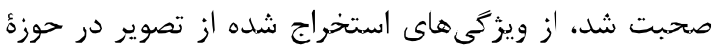
ييكسل براى هدل سازى سازوكار توجه بصرى استفاده

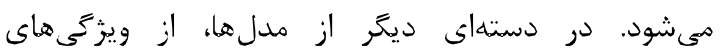

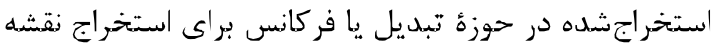

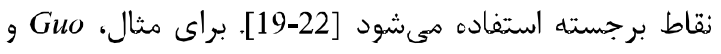

${ }^{9}$ Commission internationale de l'ćclairage

${ }^{10}$ Super-Pixels

${ }^{11}$ Objectness

${ }^{12}$ Appearance

13 Object Probability Map

${ }^{11}$ Segmentation
روشهاى بالا به پاييين سادهتر بوده و از سرعت يردازش بالاترى برخورهار هستند؛ به اين دليل، تعداد مدلهائ باد باد

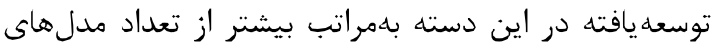

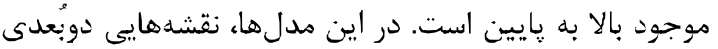

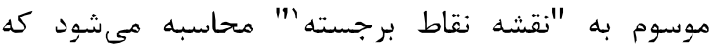
مقادير نقاط مختلف در آن، بيانكر ميزان جلب توجه بينتده به نقاط متناظر در تصوير ورودى است. بيشتر مدلهاى بايين به بالا كه از ويزگكىهاى سطح ״ايين براى هحاسبه نقشه نقاط برجسته استفاده مي كنيند،

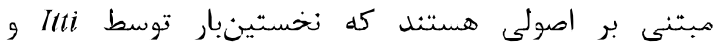

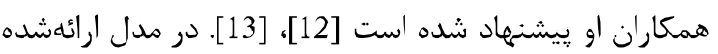
توسط Itti فرض مىشود كه نقاط برجسته در يك تصوير

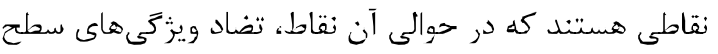

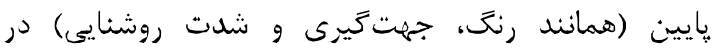
مقايسه با ساير نقاط بيشتر است؛ لذا در اين مدل، نقاط

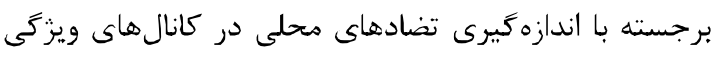

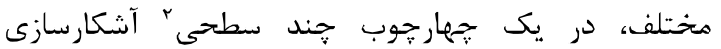

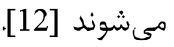

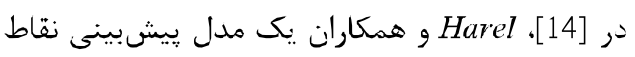

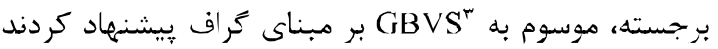
كه در آن فرض مىشود تكههايى" آز تصوير كه عدم تشابه

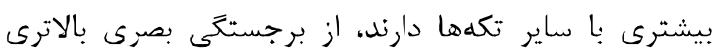

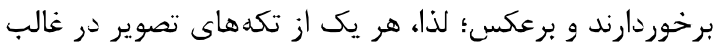

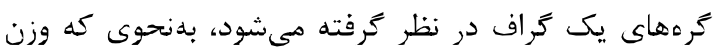
هر يال بين دو كره از تراف، برابر با ميزان عدم تشابه دو تكه

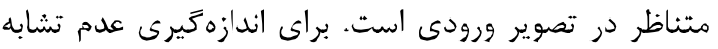
دو تكه نيز، از يك زنجيره ماركف استفاده مى شود. مشابه باليا

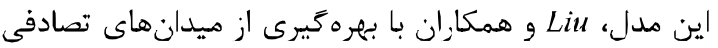

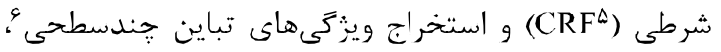

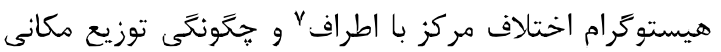
رنغ، روشى براى آشكارسازى نقاط برجسته ارائه كردند

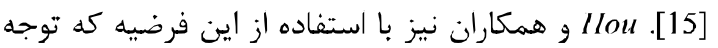
انسان به سمت نقاط با بيشترين حجم اطلاعات، جلب شود،

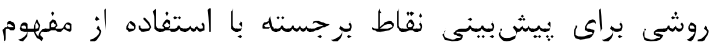

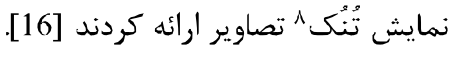

\footnotetext{
1 Visual Saliency Map

${ }^{2}$ Multiscale

${ }^{3}$ Graph-Based Visual Saliency

${ }^{4}$ Patch

${ }^{5}$ Conditional Random Ficlds

${ }^{6}$ Multi-Scale Contrast

${ }^{7}$ Center-Surround Histogram

${ }^{8}$ Sparse Representation
} 


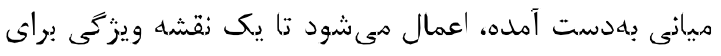

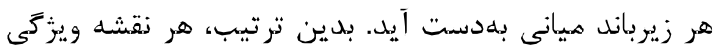

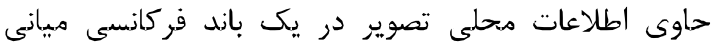

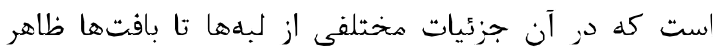

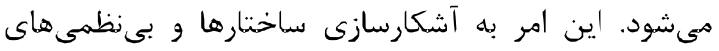

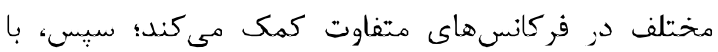

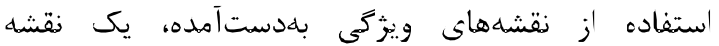
برجستخى بصرى هحلى و يك نقشه برجستى كلى كلى هحاسبه مىشود. براى محاسبه نقشه برجستئى مجحلى، ابتدا بيشينه

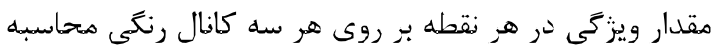

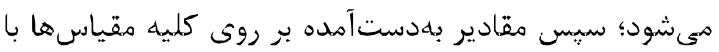

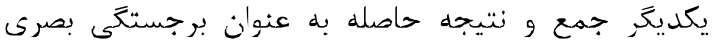
محلى در آن زقطه در نظر كرفته مى نشود. براى محاسبه نيه

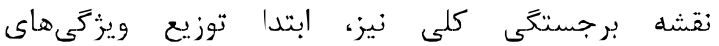

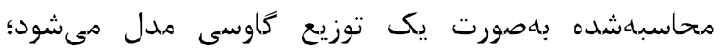

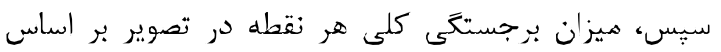

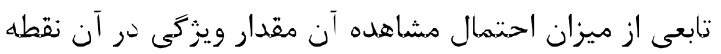

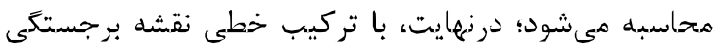
محلى و كلى بهدستآهده، زقشاه برجستخى نهائى تصوير

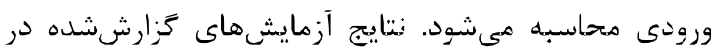

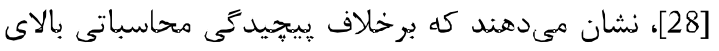

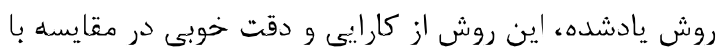
ساير روشهاى موجود برخوردار است. در اين مقاله، قصد داريم تا روش [28] را به بـونهائ تغيير دهيهم تا از بِيجيديدى محاسباتى آن كاسته شود. براى داى

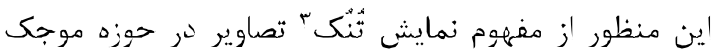

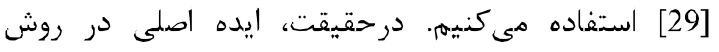

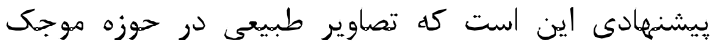

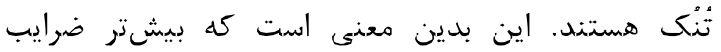
موجى تصاوير طبيعى دامنه بسيار كوجكى دارند و لذان الذا

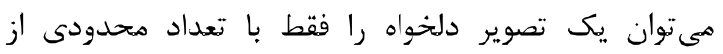

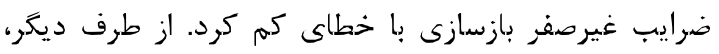

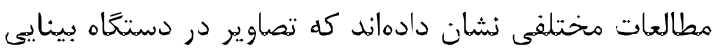

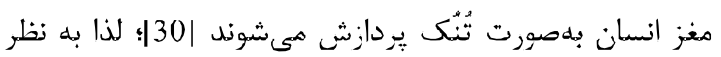

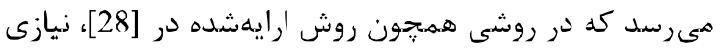

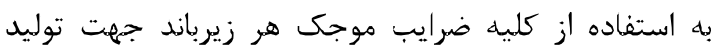
نقشه ويزگكى آن زيرباند نيست و بهاحتمال تعداد محدودى از

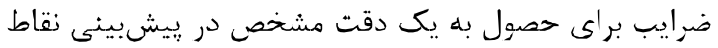

$$
\text { برجسته، كفايت مى كند. }
$$

${ }^{3}$ Sparse Representation
همكاران، مدلى جهت توليد نقشه نقاط برجسته در قابهاى

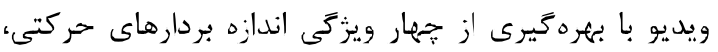

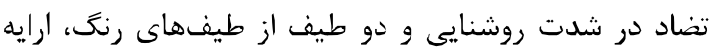

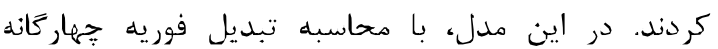

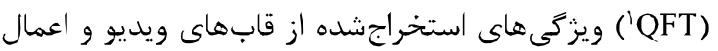
عكس تبديل QFT بر روى مرحلأ طيف نرماليزهشده، نقشه

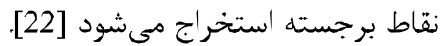

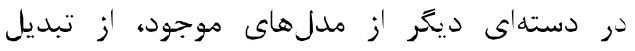

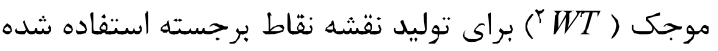

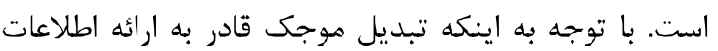
مكان فركانسى است، استفاده از اين تبديل در مدله التهاى

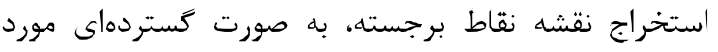

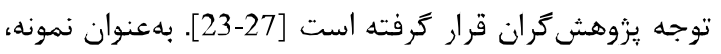
Libao

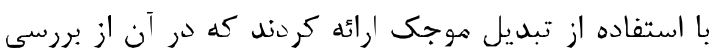

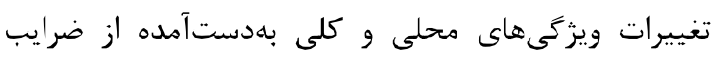

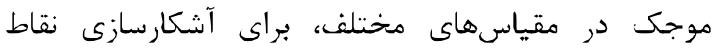

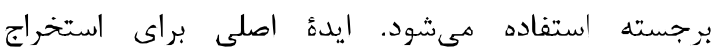

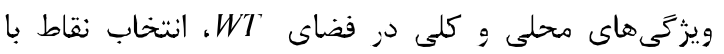

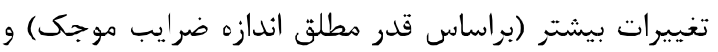

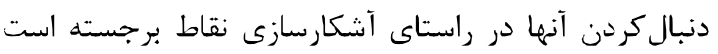

مشابه با [23]، Murry و همكاران نيز روشى ارائه

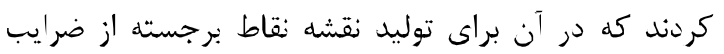

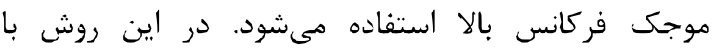
بهره

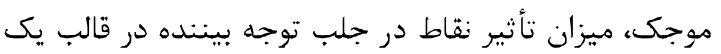

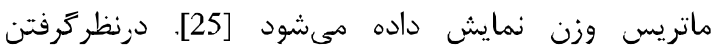
حساسيت انسان به تباين محلى و قابليت جلب توجد نقان نقاط

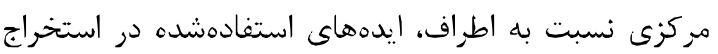
نقشه نقاط برجسته در اين روش هستند. Imamoğlu

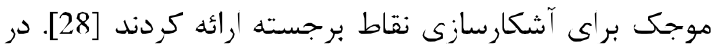
اين روش نيز مانند [17]، با توجه به نزديكى فضاى رناي رنت

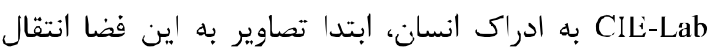

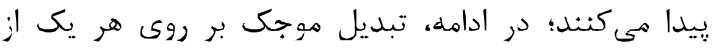

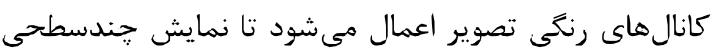

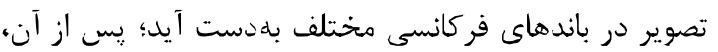

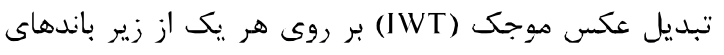

${ }^{1}$ Quaternion Fourier Transform

${ }^{2}$ Wavelet Transform 


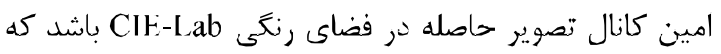

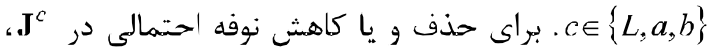

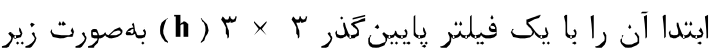

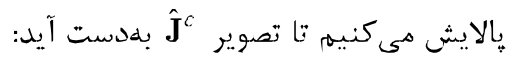

$\hat{\mathbf{J}}^{c}=\mathbf{J}^{c} * \mathbf{h}$

سبِ هريك از كانالهاى

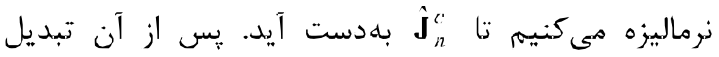

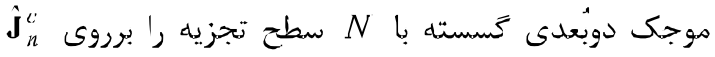
اعمال مى كنيه زا ضرايب موجك

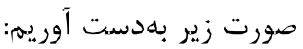

$\left[A_{N}^{c}, H_{s}^{c}, V_{s}^{c}, D_{s}^{c}\right]=W T_{N}\left(\hat{\mathbf{J}}_{n}^{c}\right)$,

كه در آن (.) $W T_{N}$ بيانكر تبديل موجك كسسته با N سطح تجزيه است و في

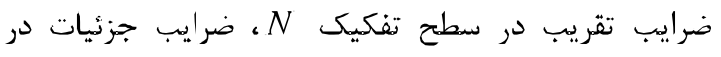

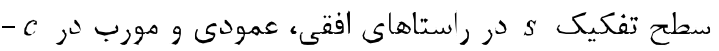
اهين كانال

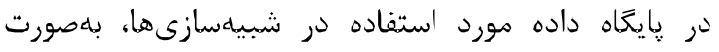

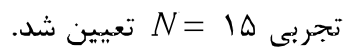
حال براى استخراج ويزّكَّهاى هورد نظر از ضرايب

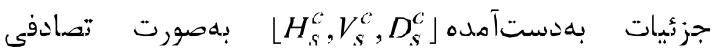

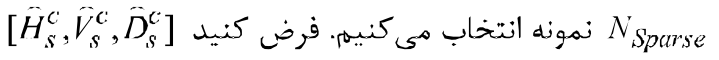
بيانكر زمونههاى بلدست آهده باشد. از اين نمونهها بهعنوان

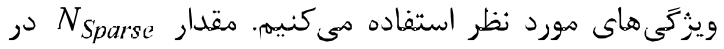

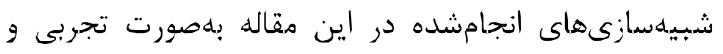
براى دستيابى به جواب برينه بر روى بِايكاه داده مورد إندان استفاده، f

\section{r-r- توليد نقشه هاى ويزگ}

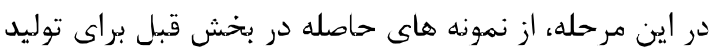

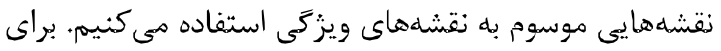
اين منظور sكس تبديل موجك در سطح s s (IWT برروى نقشه ويزّى ( بهدست آيد:

$\operatorname{Map}_{s}^{c}(x, y)=\frac{\left(I W T_{s}\left(\hat{H}_{s}^{c}, \hat{V}_{s}^{c}, \hat{D}_{s}^{c}\right)\right)^{2}}{\eta}$,

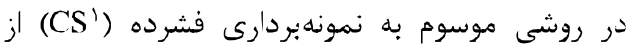

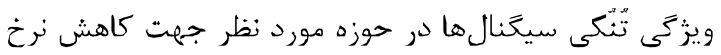

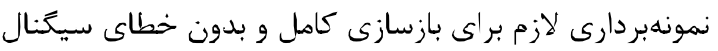

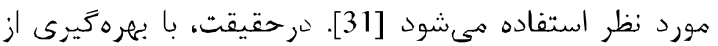

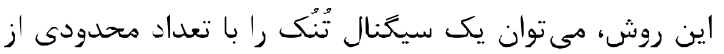
نمونهماى تصادفى با دقت بسيار بالايى بازسازى كرد. بر ائن

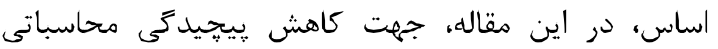

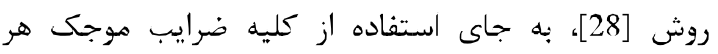

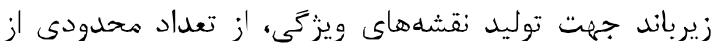
ضرايب موجك كه بهصورت تصادفى انتخاب مى نشوند،

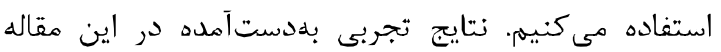

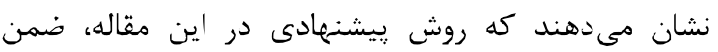
كاهش حجهم محاسباتى روش ارايهشده در |28|، قادي دادر است تا

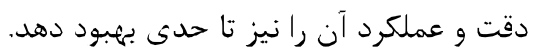

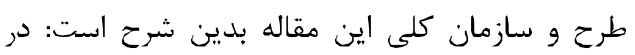

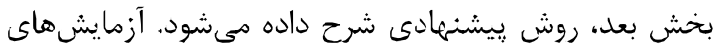

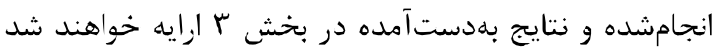

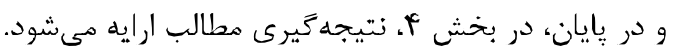

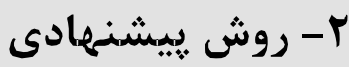

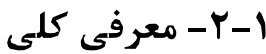

همانطوركه در بخش قبل اشاره شد، در اين دقاله روشى

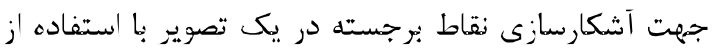
زمونهبردارى تصادفى از ضرايب موجك در زيرباندهاى تصوير

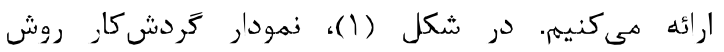

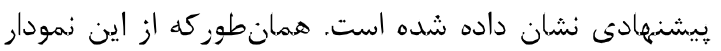

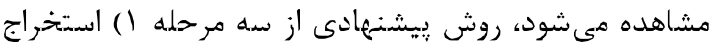

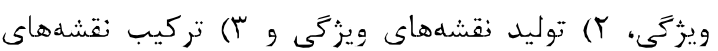
ويزكى جهي محاسبة نقشه نقاط برجسته، تشكيل شده

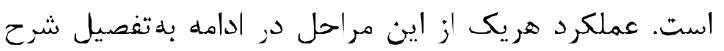

داده خواهد شد.

\section{r-r- مرحلة استخراج ويثزى} فرض كنيد يك تصوير RGB (ورودى Iال) در اختيار داريم و

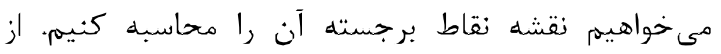

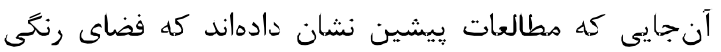
CIE-Lab

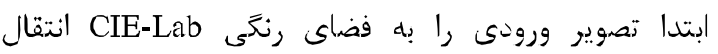

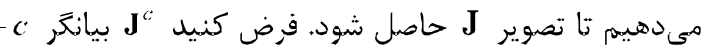

\footnotetext{
${ }^{1}$ Compressive Sampling
} 
مقياسگذارى و جلوگيرى از ايجاد تغييرات بزرگ در

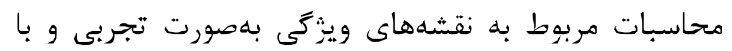

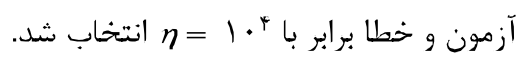

كه در آن 7 يك ثابت نرماليزهكردن است. با توجه به اينكه

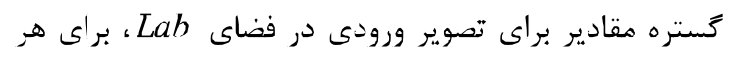

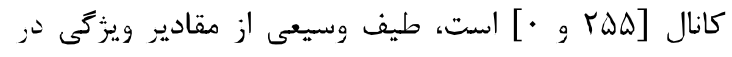
وجود دارد. مقدار $\eta \operatorname{Map}_{s}^{c}(x, y)$

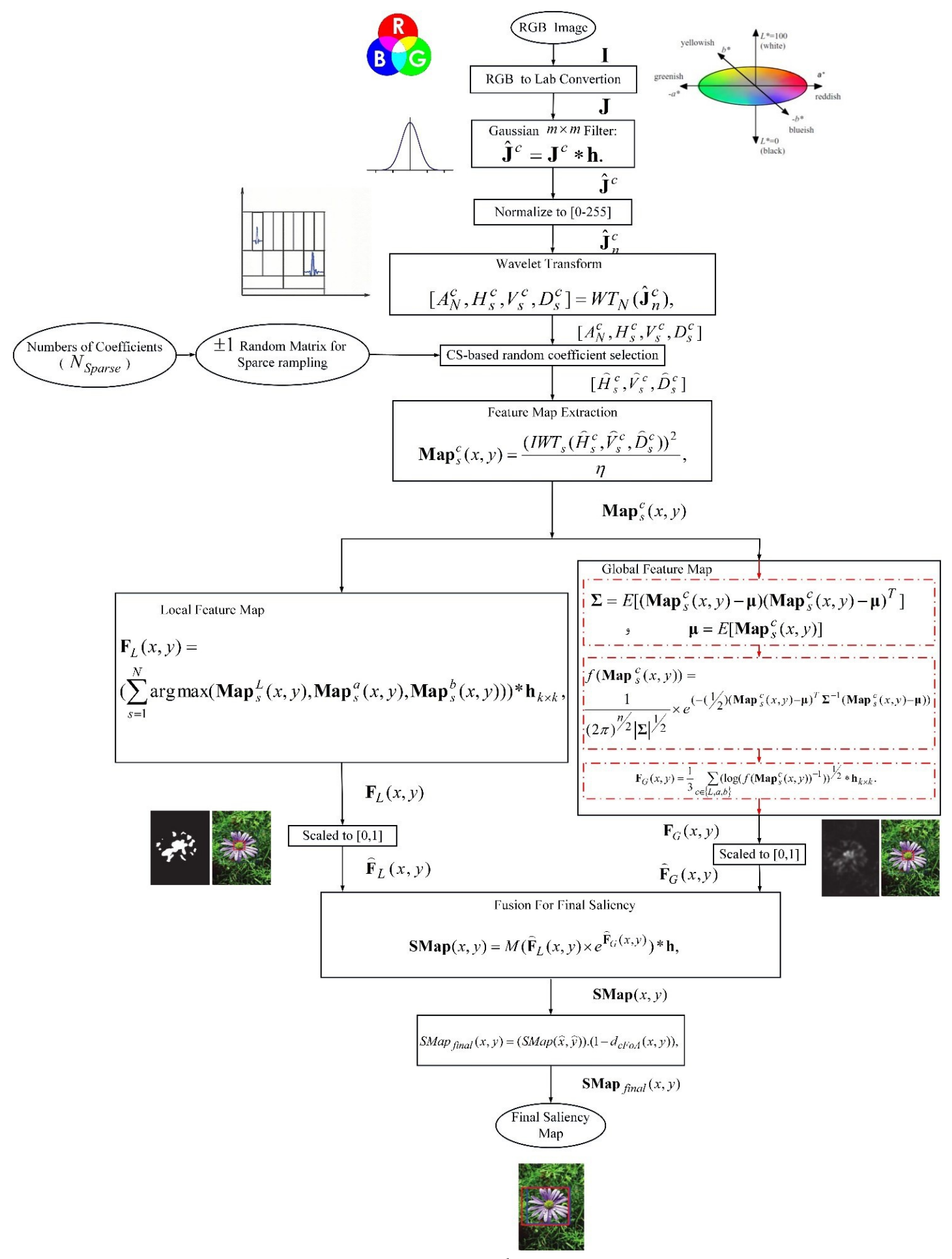

(شكل -1) : نمودار گردش كار روش ييشنهادى

(Figure-1): Flowchart of the proposed method 
مقادير ممكن براى خروجى رابطهُ (入)، با توجه به انتخاب يارامترها، بين صفر و يكى است.

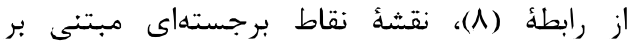

نقشهواى برجستخى محلى و كلى بلهدست مى آيد. در ايجاد

نقشه برجستخى نهايى از روشى مشابه با روش شرح دادهـده

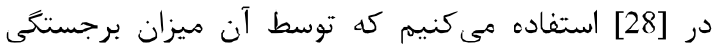
مناطق اطراف نقطهاى كه بيشترين ميزان برجستگى را دارد

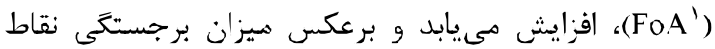

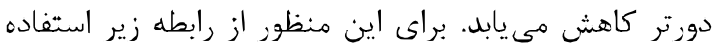
مى كنيهم:

$\operatorname{SMap}_{\text {final }}(x, y)=(\operatorname{SMap}(\bar{x}, \bar{y})) .\left(1-d_{c l o A}(x, y)\right)$,

كه در اين رابطه (xMap final نقطه (x,y)

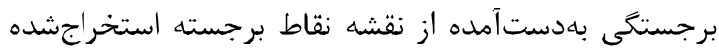
از (^) (در مكان (

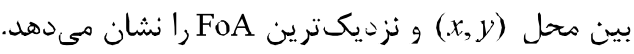

\section{r- - نتايج آزمايشهاى انجامشده}

نتايج شبيdسازىهاى انجامشده در اين مقاله، بر روى بايغاه

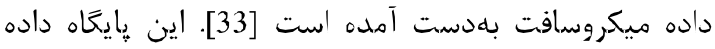

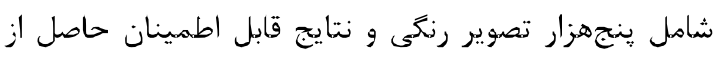
دادههاى تعقيب جشهم انسان در راستاى آشكارسازى نواحى سيى

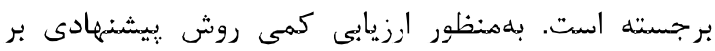

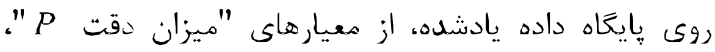

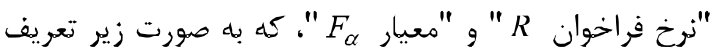
$P=\frac{\sum_{x} \sum_{y}(t(x, y) \times s(x, y))}{\sum_{x} \sum_{y}(s(x, y))}$ مىشوند، استفاده مى كنيم: $R=\frac{\sum_{x} \sum_{y}(t(x, y) \times s(x, y))}{\sum_{x} \sum_{y}(t(x, y))}$

$F_{\alpha}=\frac{(1+\alpha) \times P \times R}{\alpha \times P+R}$

در اين روابط،

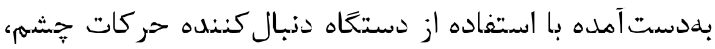

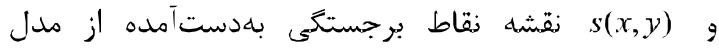

${ }^{1}$ Focus of $A$ ttention

${ }^{2}$ Ground-Truth Map

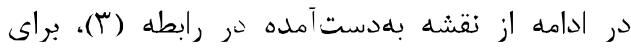
توليد يك نقشه ويزگى محلى و و يك نقشه ويزگگى كلى استفاده مى كنيم. جهت توليد نقشه ويزگى محلى درئى در هر كانال از رابطه زير استفاده مى كنيهم: $\mathbf{F}_{L}(x, y)-$

$\left.\left(\sum^{V} \operatorname{argmax}\left(\operatorname{Map}_{s}^{L}(x, y), \mathbf{M a p}_{s}^{a}(x, y), \mathbf{M a p}_{s}^{b}(x, y)\right)\right)\right)^{*} \mathbf{h}_{k \times k}$,

كه در آن آن

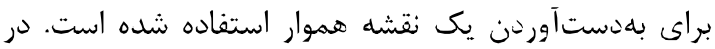
اينجا براى رسيدن به جواب بهينه در شبيهسازى بها بها با آزمون و خطا مقدار ف = = در نظر كرفته شده است.

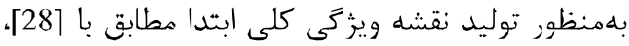

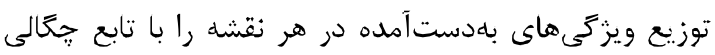

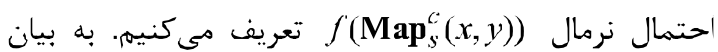

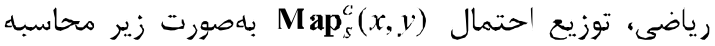
مى شود: - مئ

$f\left(\mathbf{M} \mathbf{a p}_{s}^{c}(x, y)\right)=$

$\frac{1}{(2 \pi)^{n / 2}|\Sigma|^{1 / 2}} \times e^{\left(\left((1 / 2)\left(\operatorname{Map}_{s}^{c}(x, y) \mu\right)^{T} \Sigma^{-1}\left(\operatorname{Map}_{s}^{c}(x, y) \mu\right)\right)\right.}$,

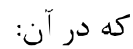

$$
\begin{aligned}
& \Sigma=E\left[\left(\operatorname{Map}_{s}^{c}(x, y)-\boldsymbol{\mu}\right)\left(\operatorname{Map}_{s}^{c}(x, y)-\boldsymbol{\mu}\right)^{T}\right] \\
& \boldsymbol{\mu}=E\left[\operatorname{Map}_{s}^{c}(x, y)\right] \\
& \mathbf{F}_{G}(x, y)=\frac{1}{3} \sum_{c \in\{L, a, b\}}\left(\log \left(f\left(\mathbf{M a p}_{s}^{c}(x, y)\right)^{-1}\right)\right)^{1 / 2} * \mathbf{h}_{k \times k} .
\end{aligned}
$$

\section{F-F-F تركيب نقشههاى ويثَى جهـ محاسبة نقشه نقاط برجسته}

براى توليد نقشه نقاط برجسته تصوير ورودى، ابتدا هريك از

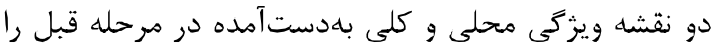

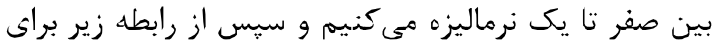

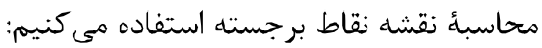

$\operatorname{SMap}(x, y)=M\left(\widehat{\mathbf{F}}_{L}(x, y) \times e^{\widehat{F}_{G}(x, y)}\right) * \mathbf{h}$,

دراين رابطه

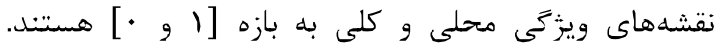

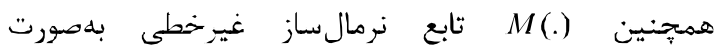

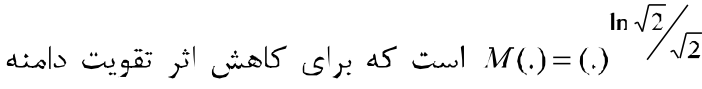
بر روى نقشه نقاط برجسته نهايى استفاده مىشود 281]. 
در انامه شبيهسازىهاى انجامشده كيفيت عملكرث

روش ييشنهادى بلصورت كمى مورد بررسى قرار مى گيردا.

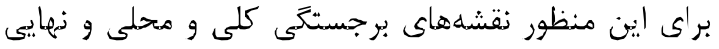

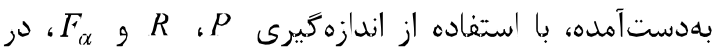
شكل (با) نمايش داده شده است. از اين شكل بلوضوح

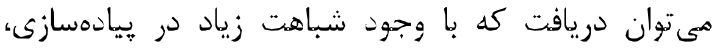

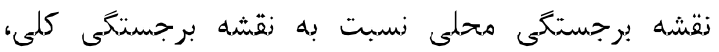
عملكرد مناسبترى نارن.

همجِنين از اين شكل مىتوان دريافت كه زتشأ برجستىى بهدستآهده از تركيب نقشههاى مجلى و كلى آنى

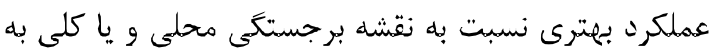

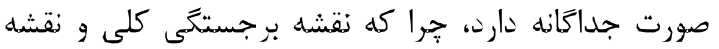

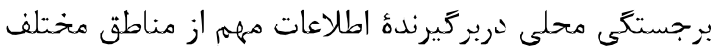

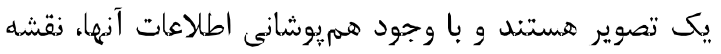

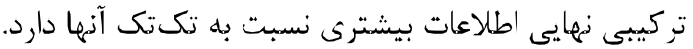
همانطوركه در بخشهاى قبل بيان شد، روشهاى

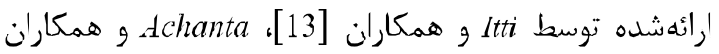

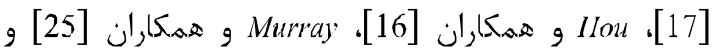
Imamoğlu

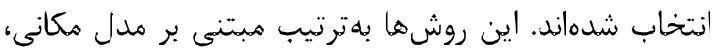
مبتنى بر تبديل فوريه و مبتنى برتبديل موجك هستندا

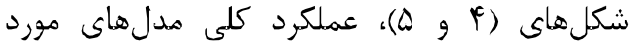
بررسى را بر اساس مقادير آستانه بهدستآمده از روش مداى

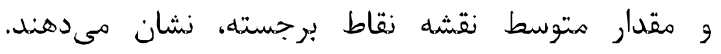

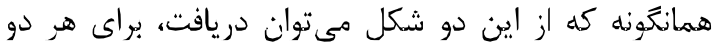
روش انتخاب آستانه، هدل ارائهششه در اين هقاله براى دهئ دعيار

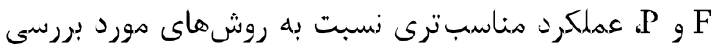

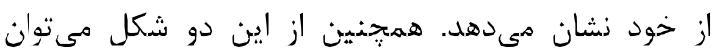
دريافت كه روش ارايهشده در [25] از ديد معيار R نسبت به آنه

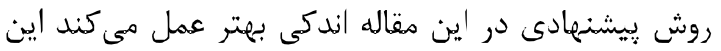

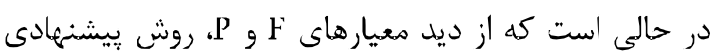
عملكرد مناسبترى دارد.

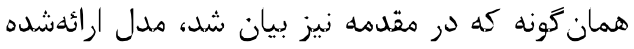

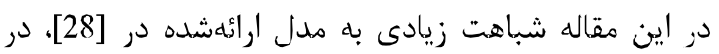
فرآيند توليد نقشههاى برجستىى محلى و كلى دارد. تفاوت اين دو مدل در جكونكى انتخاب ضرايب موجك براي توليد

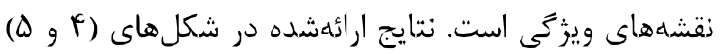
برترى نسبى روش ييشنهادى را نسبت به [28] نشان

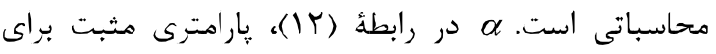

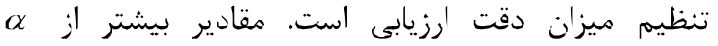

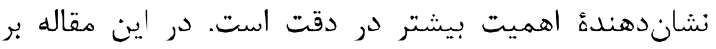

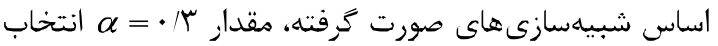

$$
\text { شده است. }
$$

در شبيهسازىها، P نشانكر ميزان كيفيت روش

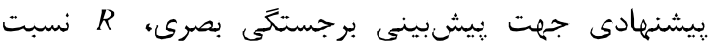
مناطق برجسته صحيح تشخيص دادهشده به بندئن اطلاعات مبنا

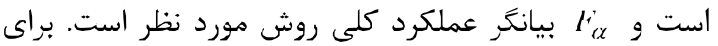

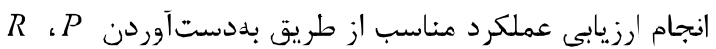

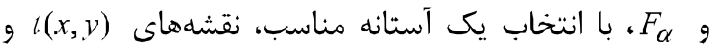

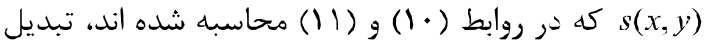
به نقشههاى دودويى مىشوند. اين مقادير آستانه توسط

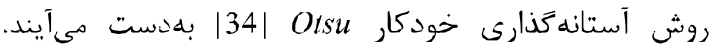
علاوهبر موارد بالا، در شبيهسازىها، عملكرد مدل يُشيشنهاني

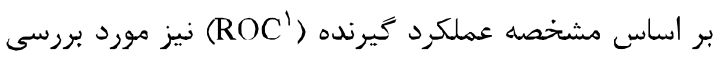

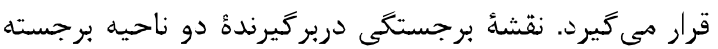
و غير برجسته است.

درصدى از مناطق برجسته كه منطبق با نقشه

برجستگى بلهدستآمده از نتايج قابل اطمينان است، نرخ

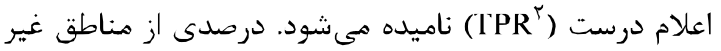

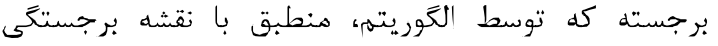
بلدستآمده از نتايج قابل اطمينان تشخيص داده مىشود،

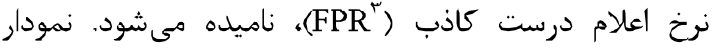

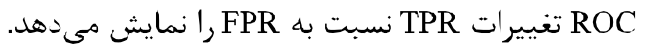
در نخستين قسمت از آزمايشها، عملكرد روش

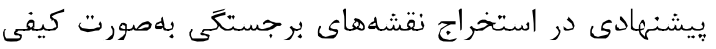

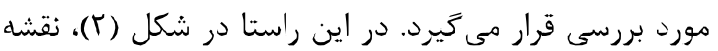

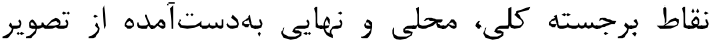

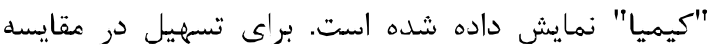

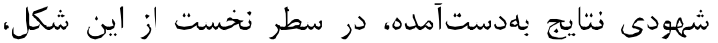

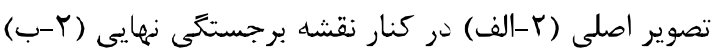

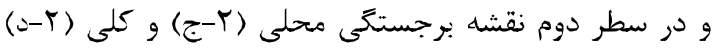

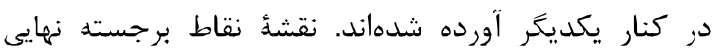

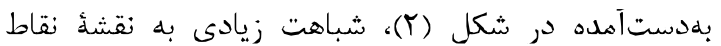

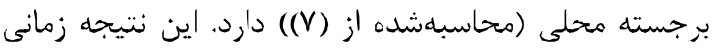
ايجاد مىشود كه توزيع ويزگكىهاى محلى براى مناطق

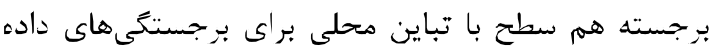

شده باشد.

\footnotetext{
${ }^{1}$ Receiver Operating Characteristic

2 True Positive Rate
}

${ }^{3}$ False Positive Rate 

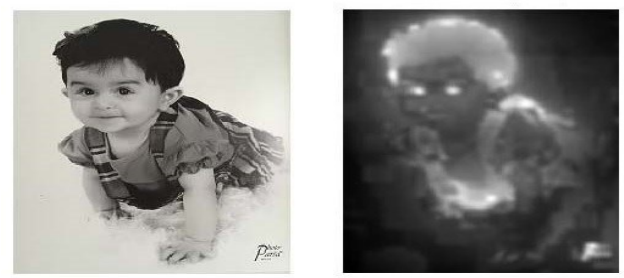

الف

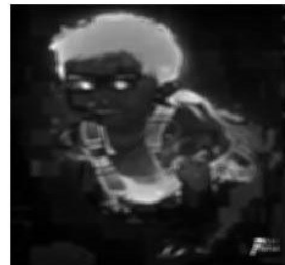

$\varphi$

ج

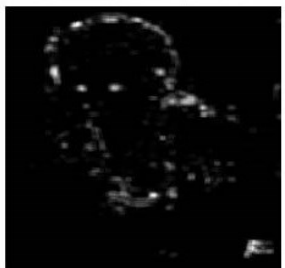

$\checkmark$

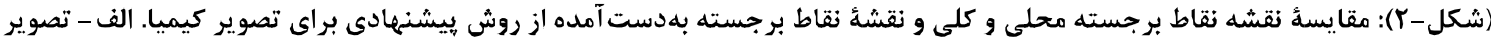

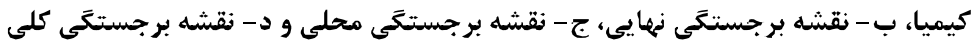

(Figure 2): An example showing local and global saliency maps from the proposed method. A) Input image, B) Final saliency map, C) Local saliency map, and D) Global saliency map

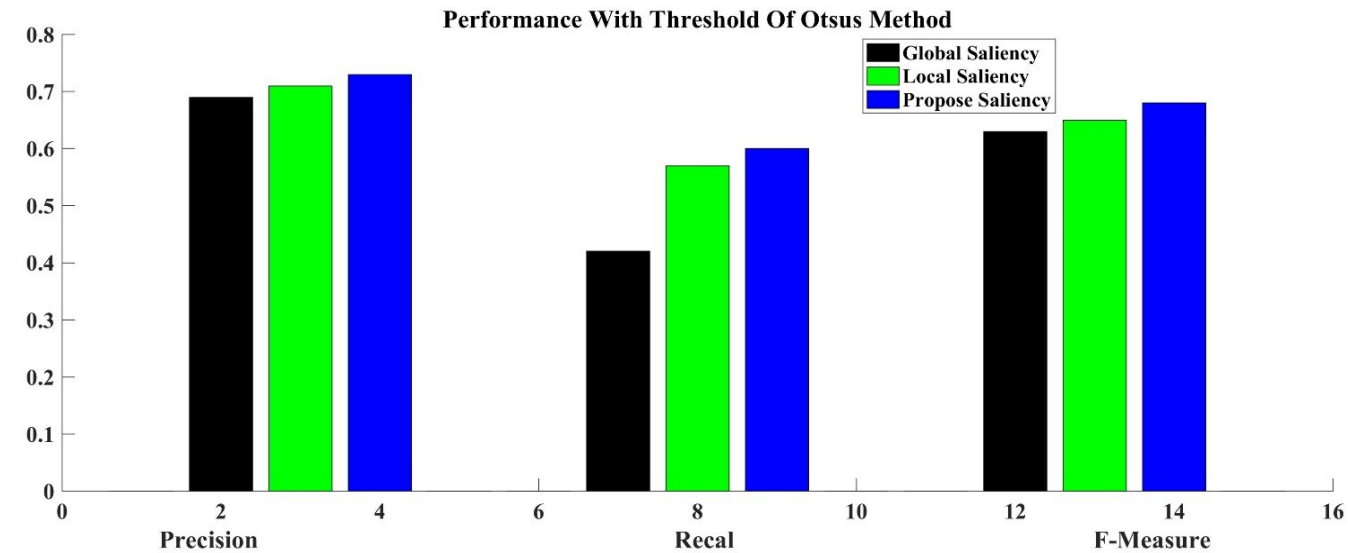

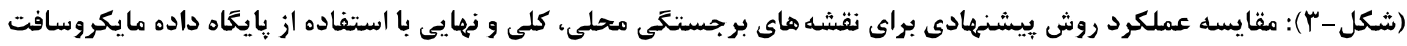

(Figure-3): performance evaluation of the proposed method for local, global, and linal Saliency maps using Microsoft's saliency dataset

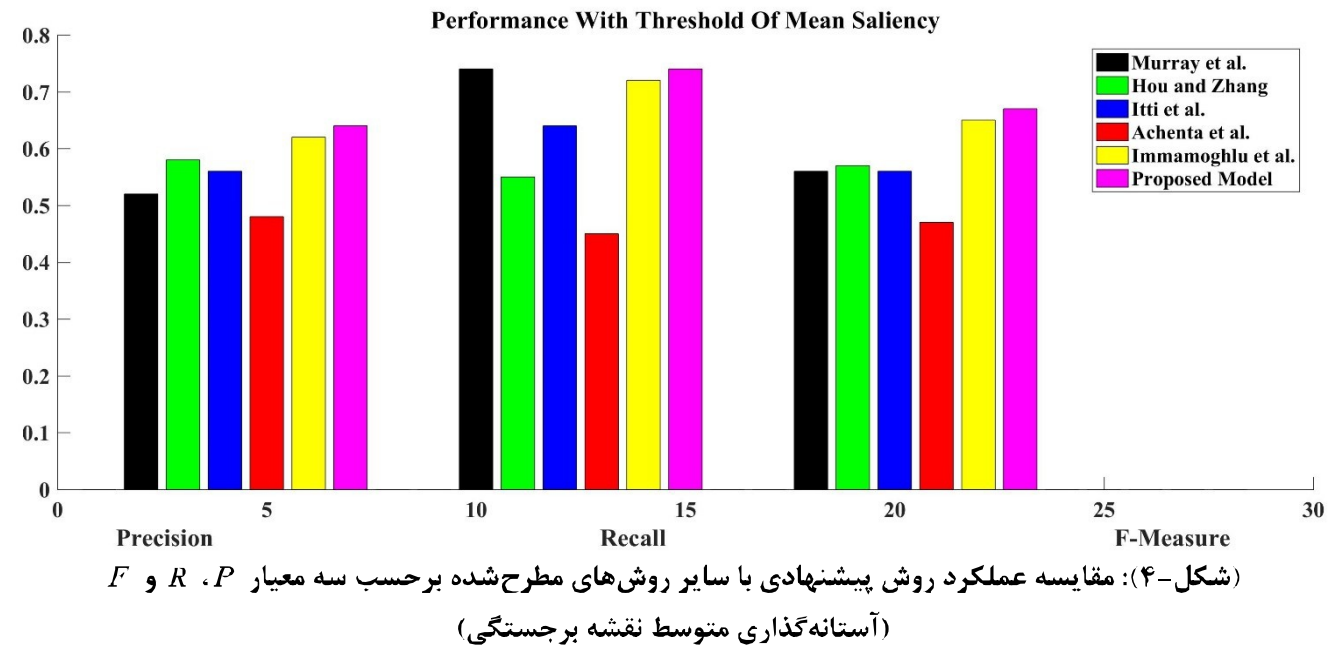

(Figure-4): performance evaluation of various saliency prediction methods in terms of precision, recall, and F-measure (middle threshold of the saliency map) 


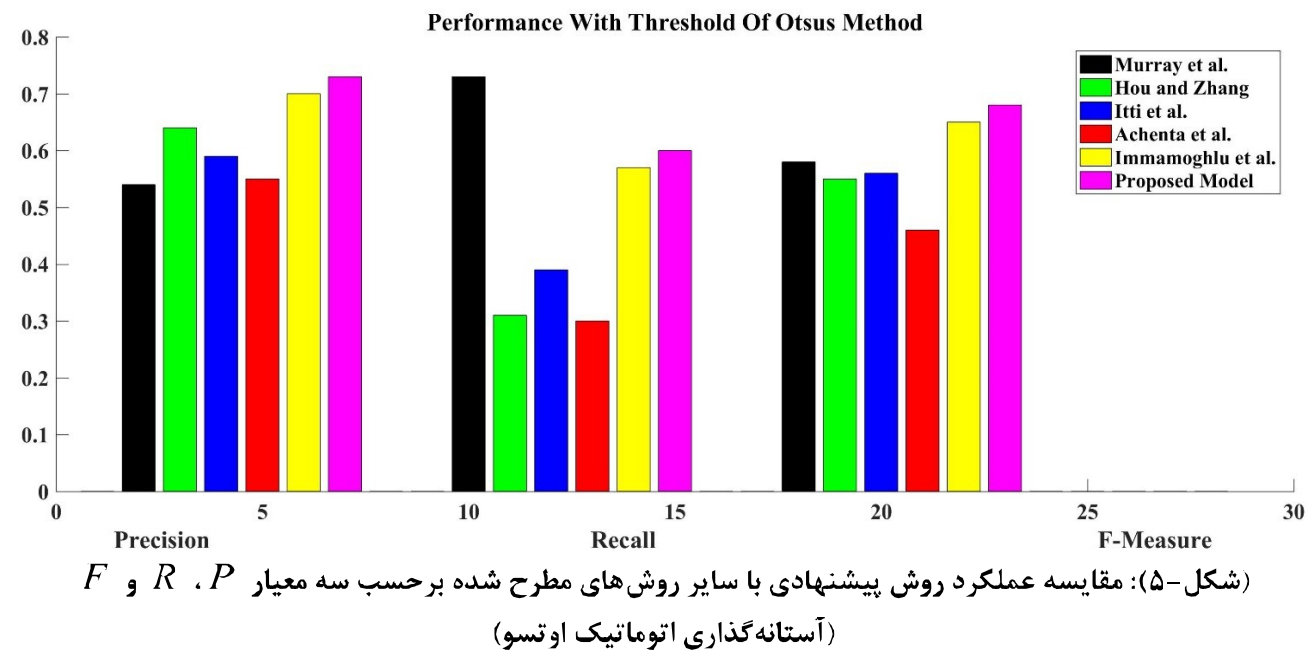

(Figurc-5): performance evaluation of various saliency prediction methods in terms of precision, recall, and F-measurc (Ottsu's Autothresholding)

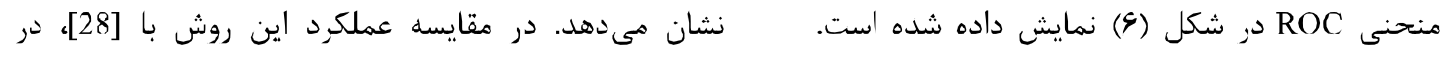

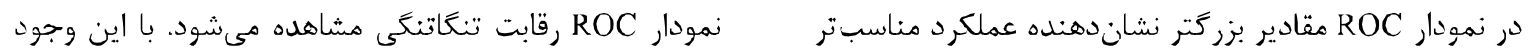

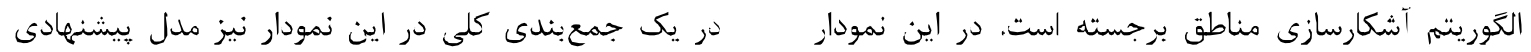

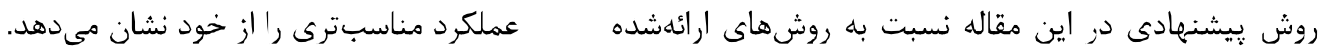

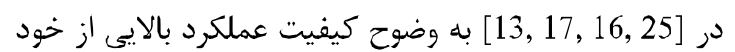

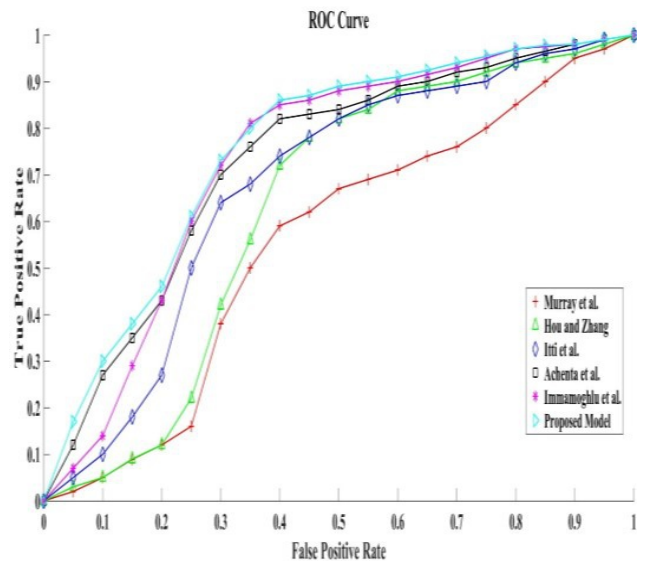

ROC شكل - (צ): مقايسه روش پييشنهادى و ساير روشها توسط نمودار

(Figure-6): evaluating ROC diagrams for various saliency prediction models.

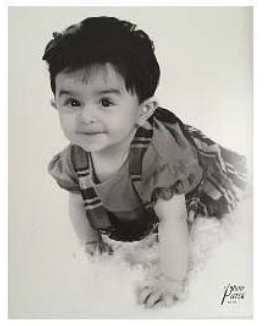

الف

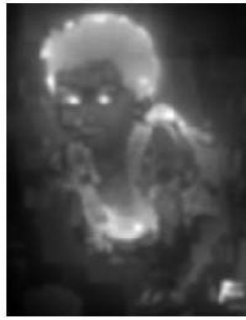

ب

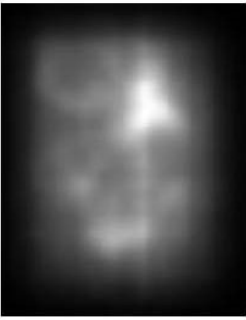

ج

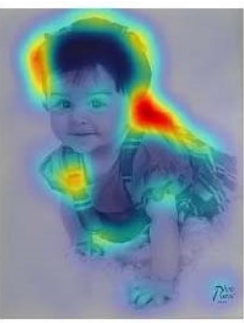

ง

(شكل - V): مقايسهٔ نقشأ نقاط برجسته بهدست آمده از روش بيشنهادى و دو روش ديكر براى تصوير كيميا. الف - تصوير كيميا، ب- روش

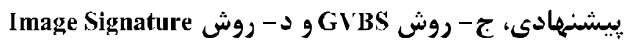

(Figure-7): A demonstration of saliency maps generated from different approaches: A) Input image, B) Proposed algorithm, C) GVBS method, D) Image Signature method. 
(جدول-(): مقايسةً نقشهُ نقاط برجسته بهدست آمده از روش بيشنيهادى و دو روش ديكر براى تصوير كيميا بر اساس متوسط زمان اجرا.

(Table-1): Comparison of the proposed method with other classic methods in terms of average computational time.

\begin{tabular}{|c|c|c|c|c|c|c|c|c|}
\hline شده در الرايه| & شده مر ارايه & شده در |13| رايه| & شده درش ارايه| & شده در الرايه & شده در ارليه & شده در ارايه & ييشنهلانى روش & نام روش \\
\hline 0.2913 & 0.3109 & 0.4102 & 0.2152 & 0.5249 & 0.4015 & 0.3801 & 0.1801 & هدات زمان \\
\hline
\end{tabular}

اذجامشده نشان مىدهند كه اين روش از كارايى و دقت

خوبى در مقايسه با ساير روشهاى موجود برخوردار و در

$$
\text { عين حال زمان اجراى كمترى دارد. }
$$

\section{5- References}

$$
\text { ه - مراجع }
$$

[1] Y. Fang, W. Lin, Zh. Chen, Chia-Ming Tsai, and Chia-Wen Lin, "A Video Saliency Detection Model in Compressed Domain", IEEE Trans. Circuits and Systems for Video Technology, vol. 24, no. 1, Jan. 2014.

「2† S. Mathe and C. Sminchisescu, "Actions in the Eye: Dynamic Gaze Datasets and Learnt Saliency Models for Visual Recognition", IEEE Trans. Pattern Analysis and Machine Intellegence, vol. 37, no. 7, Jul 2015.

[3] S. H. Khatoonabadi, I. V. Bajc, Yufeng Shan, "Comparison of visual saliency models for compressed video", in Proc. IEEE International Conference on Image Processing (ICIP), Jan 2015.

[4] M. Xu, L. Jiang, X. Sun, Zhaoting Ye, and Z. Wang, "Leaming to Detect Video Saliency with HEVC Features", IEEE Trans. Image Procesing, vol. 26, no. 1, Jan 2017.

[5] C. Li, Q. Tu, M. Zhao, J. Xu and A. Men, "A multiscale compressed video saliency detection model based on ant colony optimization", in Proc. IEEE CIC/ICCC 2015 Symposium on Signal Processing for Communications, Nov. 2015.

[6] M. Jiang, X. Boix, G. Roig, J. Xu, L. V. Gool and Q. Zhao, "Learning to Predict Sequences of Human Visual Fixations", IFEE Trans. Neural Networks and Learning Systems, vol 27, no.6, Jun 2016 .

| حسين فياضى، حميد دهقانى، مجتبى حسينى، "تجزية

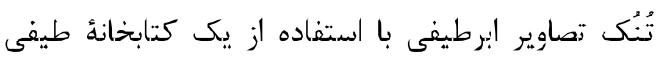

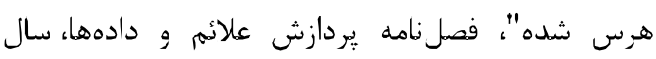

سيزدهم شماره r (بيايى 9 9.

.1790

[7] H.Fayazi, H.Dehqani, and M.Hosseini,"sparse unmixing of hyper-spectral images using a pruned
در شكل (V)، روش ييشنهلادى در مقايسه با روش

ق [14] GVBS

قرار مى عيرد. نتايج بهدستآمده ارائه شده است. در اين شكل برترى روش بيشنههادى قابل مشاهده است.

در قسهت آخر ز شبيهسازىهاى انجامشده مدت

زمان اجراى متوسط روش بيشنهادى، بهعنوان يك تخمين

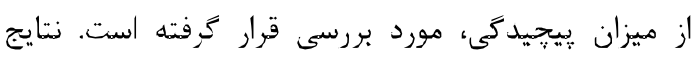

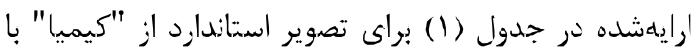

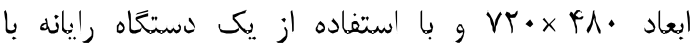
يردازيده Core i7 6700HQ و فركانس :ودازش T/9 GHz،

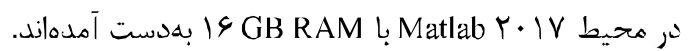
نتايج بهدستآمده نشاندهنده سرعت بالاى روش ييشنهادى در استخراج نقشه زقاط بوجسته هستند. دليل

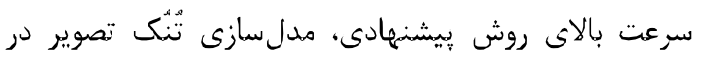

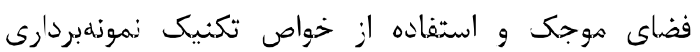
تصانفى است.

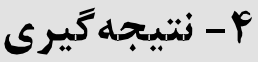

در اين مقاله، زوشى براى بيش بينى نقاط برجسته در

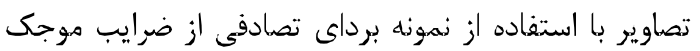

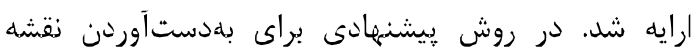

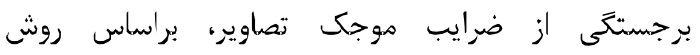

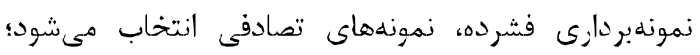
سيّى از نمونههاى تصادفى انتخابششه در هر زيرباند ميانى، معكوس تبديل موجك گرفته شده تا زقشههايى موسوم به

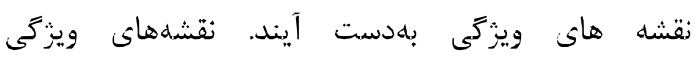
بهدستآمده حاوى اطلاعات محلى تصوير در يكى باند فركانسى ميانى است كه در آن جزئيات مختلفى از لبهها تا

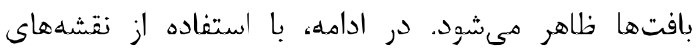
ويزّى بهدست آهده، نقشه برجستخى بصرى محلى و نقشه

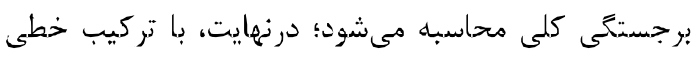

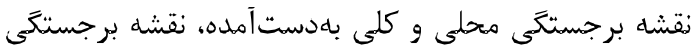

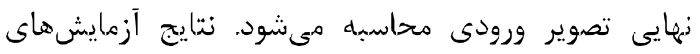


IEEE Trans. Multimedia, vol. 19, no. 8, pp. 1742 - 1756, Apr 2017.

[19] L. Zhang, X. Li, L. Nie, Y. Yang, and Y. Xia, "Weakly Supervised Human Fixations Prediction", IEEE Trans. Cybernetics, vol. 46, no. 1, pp. 258 - 269, Jan. 2016.

[20] J. Li, L. Duan, X. Chen, T. Huang, and Y. Tian, "Finding the Secret of Image Saliency in the Frequency Domain", IEEE Trans. Pattern Analysis and Machine Intellegence, vol. 37, no. 12, pp. 2428-2440, Apr 2015.

[21] X. Hou and L. Zhang, "Saliency detection: A spectral residual approach," in Proc. IEEE Int. Conf. Comput. Vision and Pattern Recognition, pp. 1-8, Nov. 2007.

[22] C. Guo, Q. Ma, and L. Zhang, "Spatio-temporal saliency detection using phase spectrum of quaternion Fourier transform," in Proc. IEEE Int. Conf. Comput. Vision and Pattern Recog-nition, pp. 1-8, 2008.

[23] L. Zhang, J. Chen, and B. Qiu, "Region-ofInterest Coding Based on Saliency Detection and Directional Wavelet for Remote Sensing Images", IEEE Trans. Geoscience and Remote Sensing Letters, vol. 14, no. 1, pp. 23-27, Jan 2017.

[24] Y. Yang, Y. Que, Sh. Huang, and P. Lin, "Multiple Visual Features Measurement with Gradient Domain Guided Filtering for Multisensor Image Fusion", IEEE Trans. Instrumentation and Measurement, vol. 66, no. 4, Apr 2017.

[25] N. Murray, M. Vanrell, X. Otazu, and C. $\Lambda$. Parraga, "Saliency estimation using a non-parametric low-level vision model," in Proc. IEEE Int. Conf. Comput. Vision and Pattern Recognition, 2011.

[26] X. Liu, D. Zhai, J. Zhou, X. Zhang, D. Zhao, and Wen Gao, "Compressive Sampling-Based Image Coding for Resource-Deficient Visual Communication", IEEE Trans. Image Procesing, vol. 25, no. 6, Jun 2016.

[27] M. Aghagolzadeh, H. Radha, "Joint Estimation of Dictionary and Image from Compressive Samples", IEEE Trans. Computational Imaging, vol. pp, no. 99, Feb 2017.

[28] N. İmamoğlu, W. Lin, Y. Fang, "A Saliency Detection Model Using Low-Level Features Based on Wavelet Transform", IEEE Trans. Multimediu, vol. 15, no. 1, pp. 96-106, Jan 2013.

[29] S. A. Raza Naqvi, "Image compression using haar wavelet based tetrolet transform", in Proc. IEEE Int. Conf. Open Source Systems and Technologies (ICOSST), pp. 50-54, Jan 2014. spectral library", signal and data processing, no.13, pp.155-169, 1395.

$$
\begin{aligned}
& \text { [ [N] مهدى بنى طالبى دهكردى، محمد تقى صادقى، حميد }
\end{aligned}
$$

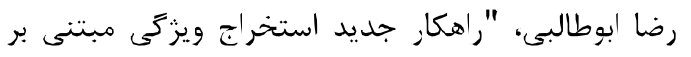

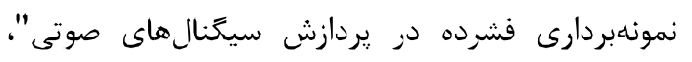

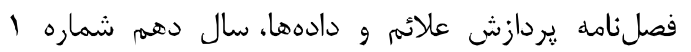

$$
\begin{aligned}
& \text { (ييايى •l) }
\end{aligned}
$$

[8] M,Bani Talebi.D, M.T.Sadeqi, and II.R. Aboutalebi, "New comprehensive sampling based feauture extraction method and its APPLICATION in audio signal processing", signal and data processing, no.01,pp.57-68,1392.

[9] N. Li, J. Ye, Y. Ji, H. Ling and J. Yu, "Saliency Detection on Light Ficld", IEEE Trans. Pattern Analysis and Machine Intellegence, vol. 39, no. 8, Aug 2017.

[10] S. Tajima and K. Komine, "Saliency-Based Color Accessibility", IEEE Trans. Image Procesing, vol. 24, no. 3, Mur 2015.

[11] S. Frintrop, "VOCUS: A visual attention system for object detection and goal directed search," Ph.D. dissertation, Rheinische Friedrich-Wilhelms-Universi" tat Bonn, Bonn, Germany, 2005.

[12] L. Itti, "Models of bottom-up and top-down visual attention," Ph.D. dissertation, Dept. Computat. Neur. Syst., California Inst. Technol, Pasadena, 2000.

[13] L. Itti, C. Koch, and E. Niebur, "Model of saliency-based visual attention for rapid scene analysis," IEEE Trans. Pattern Anal. Mach. Intell., vol. 20, no. 11, pp. 1254-1259, Nov. 1998.

[14] J. Harel, Ch. Koch, P. Perona, "Graph-Based Visual Saliency", Advances in Neural Information Processing Systems, No.19. MIT Press, Cambridge, MA, pp. 545-552, 2007.

[15] T. Liu, J. Sun, N.-N. Zheng, X. Tang, and H.-Y. Shum, "Learning to detect a salient object," in Proc. IEEE Int. Conf. Comput. Vision and Pattern Recognition, pp. 1-8, Apr. 2007.

[16] X. Hou, J. Harel, and Ch. Koch, "Image Signature: Hlighlighting sparse salient regions", IEEE Trans. Pattern Analysis and Machine Intelligence, vol. 34, no. 1, pp. 194-201, Jan 2012.

[17] R. Achanta, S. Hemami, F. Estrada, and S. Susstrunk, "Frequencytuned salient region detection", in Proc. IEEE Int. Conf. Comput. Vision and Pattern Recognition, pp. 1597 1604, 2009.

[18] L. Ye, Z. Liu, L. Li, L. Shen, C. Bai, and Yang Wang, "Salient Object Segmentation via Effective Integration of Saliency and Objectness", 
كازادا دريافت كرنداند و از سال • وجا بهعنوان استاديار در دانشخاه فردوسى مشهل فعاليت علمىى مى كنند. زمينههاى

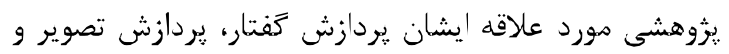
ويديو، بينايى ماشين و يردازش سيخنال هاي حياتى است. نشانى رايانامه ايشان عبارت است ازئ ماسين

a.ebrahimi $($,um.ac.ir

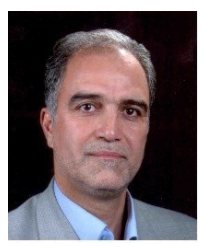

مرتضى خادمى تحصيلات خود را در هقاطع كارشناسى و كارشناسى ارشد مهندسى برق بلهترتيب در سالهاى

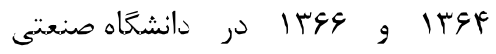
اصفهران به پِيان رسانده است. نامبرده از

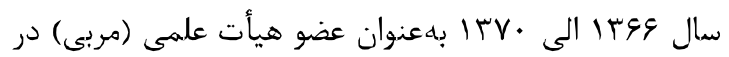

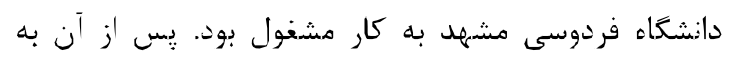
دوره دكتراى مهندسى برق در دانشخاه ولوزخوزگ (استراليا) وارد گرديده و در سال IYVF موفق به اخذ درجه دكترا در بهر ههندسى برق از دانشعاه يادشده شد. دكتر خادهى از سال IYVF مشغول به فعاليت شد و اينك زيز استاد اين دانشكده است. زمينهاى علهى دورد علاقه زاهبرده شاهل هوضوعاتى هانند

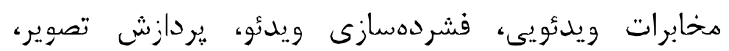

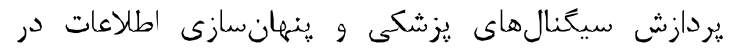
ويدئو است.

\section{khademi $(a)$ um.ac.ir}

$$
\text { نشانى رايانامه ايشان عبارت است اسز: }
$$

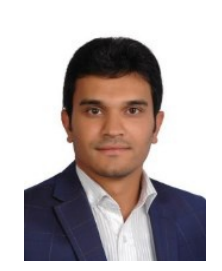

هادى هادىزاده مدرك كارشناسى و

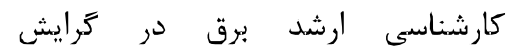
الكترونيك خود را بهترتيب از دانشعاه صنعتى شاهرود در سال IrAF علمى و صنعت ايران در سال كرده است. وى مدرك دكتراى خود را در رشته برق كرايش

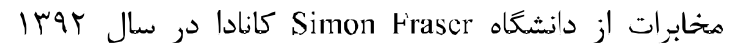
دريافت كرده و از همان سال بهعنوان استاديار در دانثعاه صنعتى قو ७ان فعاليت هى كند. زمينهایى يزوهشى مورد علاقه ايشان يردازش و فشردهسازى تصاوير و ويديوهاى ديجيتال، شبكههاى مخابراتى، بينايى و آموزش ماشين، بازشناسى الكو و مدلسازى دستخاه بينايیى مغز انسان
[30] N. D. B. Bruce, Sh. Rahman, D. Carrier, "Sparse Coding in Early Visual Representation: From Specific Properties to General Principles", Neurocomputing, vol. 2, no. 1, pp. 1085-1098, Aug 2015.

[31] M. Banitalebi-Dehkordi, $\Lambda$. BanitalebiDehkordi, J. Abouei, K. N. Plataniotis, "Face recognition using a new compressive sensingbased feature extraction method", Multimedia Tools and Applications, vol. 1, no.2, pp.1-21, Jul. 2017.

[32] S. Goferman, L. Zelnik-Manor, and A. Tal, "Context-aware saliencydetection," in Proc. IEEE Int. Conf. Comput. Vision and Pattern Recognition, pp. 2376-2383, 2010.

[33] Microsolt Rescarch Cambridge-12 database, available in: https://www.microsoft.com/en-us/download/details.aspx? id $=52283 \&$ from $=\mathrm{h}$ ttp $\% 3 \mathrm{~A} \% 2 \mathrm{~F} \% 2 \mathrm{Fresearch}$. microsoft.com $\% 2 \mathrm{Fenu}$ s\%2Fum $\% 2$ Fcambridge $\% 2$ Fprojects $\% 2 F m s r c 12$ $\% 2 \mathrm{~F}$, April, 2012.

[34] S. Theodoridis and K. Koutroumbas, Pattern Recognition, 4th ed. London, U.K.: Academic/Elsevier, pp. 20-24, 2009.

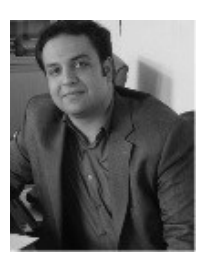

مهدى بنىطالبى دهردى دوره كارشناسى خود را در رشته مهندسى برق كرايش الكترونيك در טانشگاه شهركرد در سال عیז| به يايان رسانده و در سال |qس| مدرك كارشناسىارشد خود را در رشته مهندسى برق كرايش مخابرات سيستهم از دانشخاه يزن

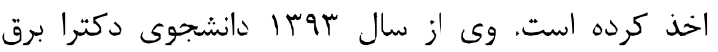
كرايش مخابرات سيستم در دانشًَاه فردوسى مشرهد است. زمينههاى يثرهشى مورد علاقه ايشان يردازش كَّتار، يردازش تصوير و ويديو و بلصورت خاص تعيين كيفيت ويديو است. نشانى رايانامه ايثان عبارت است ازئ

\section{Mehdi.banitalebidehkordi@mail.um.ac.ir}

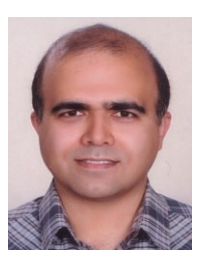

عباس ابراهيمى مقدم مدرك كارشناسى برق كرايش الكترونيك خود را از دانشعاه صنعتى شريف در سال • ITV و در سال

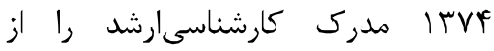
دانشعاه صنعتى خواجهنصير اخذ كرده ست. ايشان مدرك دكتراى خود را از دانشگًاه McMaster 
مىباشد. دكتر هادىزاده از سال 9. 9.ب تاكنون، موفق بـ

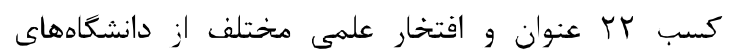

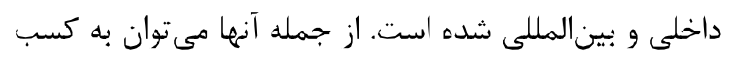

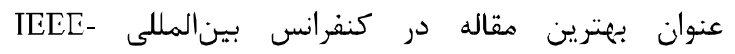

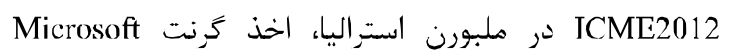
Canon Information Systems Research g Research و و اخذ عنوان بهترين مقاله كنفرانس Australia (CiSRA)

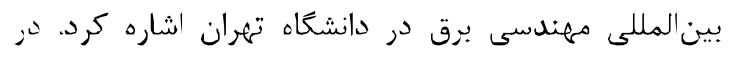

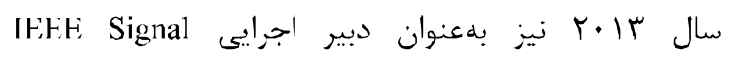
Processing Society

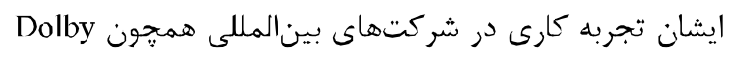

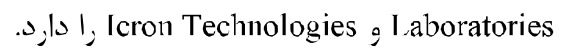
نشانى رايانامه ايشان عبارت است از: h.hadizadeh@qiet.ac.ir

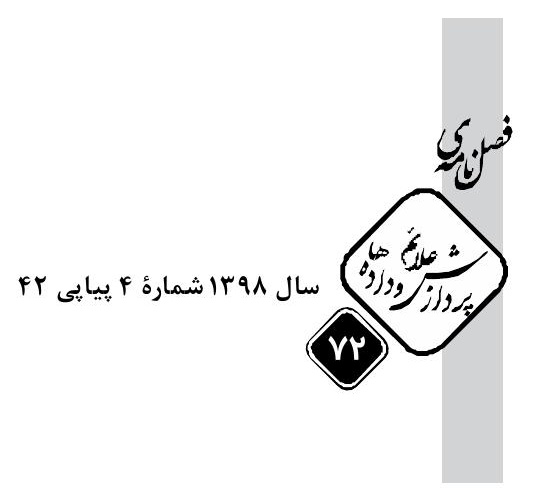

